\title{
Electrosynthesis and characterization of gold nanoparticles for electronic capacitance sensing of pollutants
}

\author{
Nicola Cioffi, Lorenzo Colaianni, Eliana Ieva, Rosa Pilolli, Nicoletta Ditaranto, \\ Maria Daniela Angione, Serafina Cotrone, Kristina Buchholt, Anita Lloyd Spetz, \\ Luigia Sabbatini and Luisa Torsi
}

\section{Linköping University Post Print}

N.B.: When citing this work, cite the original article.

Original Publication:

Nicola Cioffi, Lorenzo Colaianni, Eliana Ieva, Rosa Pilolli, Nicoletta Ditaranto, Maria Daniela Angione, Serafina Cotrone, Kristina Buchholt, Anita Lloyd Spetz, Luigia Sabbatini and Luisa Torsi, Electrosynthesis and characterization of gold nanoparticles for electronic capacitance sensing of pollutants, 2011, ELECTROCHIMICA ACTA, (56), 10, 3713-3720. http://dx.doi.org/10.1016/j.electacta.2010.12.105

Copyright: Elsevier Science B.V., Amsterdam. http://www.elsevier.com/

Postprint available at: Linköping University Electronic Press http://urn.kb.se/resolve?urn=urn:nbn:se:liu:diva-68228 


\title{
ELECTROSYNTHESIS AND CHARACTERIZATION OF GOLD NANOPARTICLES FOR ELECTRONIC CAPACITANCE SENSING OF POLLUTANTS
}

\author{
Nicola Cioffi ${ }^{1 *}$, Lorenzo Colaianni ${ }^{2}$, Eliana Ieva ${ }^{3}$, Rosa Pilolli $^{1}$, Nicoletta Ditaranto ${ }^{1}$, Maria Daniela \\ Angione $^{1}$, Serafina Cotrone ${ }^{1}$, Kristina Buchholt ${ }^{4}$, Anita Lloyd Spetz ${ }^{4}$, Luigia Sabbatini ${ }^{1}$, Luisa \\ Torsi $^{1}$ \\ ${ }^{I}$ Dipartimento di Chimica, Università degli Studi di Bari, via Orabona 4,70126 Bari, Italy \\ ${ }^{2}$ Schaefer South East Europe SRL Italy Piazza Umberto Merlin 11, I-45100, Rovigo, Italy \\ ${ }^{3}$ Solvay Solexis SpA, Spinetta Marengo, Piazzale Donegani 5/6, 15122 Alessandria Italy \\ ${ }^{4}$ Department of Physics, Chemistry and Biology, Linköping University, 58183 Linköping, Sweden \\ cioffi@chimica.uniba.it
}

\begin{abstract}
In the present study, gold/surfactant core/shell colloidal nanoparticles with a controlled morphology and chemical composition have been obtained via the so-called sacrificial anode technique, carried out in galvanostatic mode. As synthesized Au-NPs had an average core diameter comprised between 4 and $8 \mathrm{~nm}$, as a function of the electrochemical process experimental conditions. The UVVis characterization of gold nanocolloids showed clear spectroscopic size effects, affecting both the position and width of the nanoparticle surface plasmon resonance peak.

The nanomaterial surface spectroscopic characterization showed the presence of two chemical states, namely nanostructured $\mathrm{Au}^{(0)}$ (its abundance being higher than 90\%) and $\mathrm{Au}^{(\mathrm{I})}$. $\mathrm{Au}-\mathrm{NPs}$ were then deposited on the top of a capacitive Field Effect sensor and subjected to a mild thermal annealing aiming at removing the excess of stabilizing surfactant molecules. Au-NP sensors were tested towards some gases found in automotive gas exhausts. The sensing device showed the largest response towards $\mathrm{NO}_{\mathrm{x}}$, and much smaller -if any- responses towards interferent species such as $\mathrm{NH}_{3}, \mathrm{H}_{2}, \mathrm{CO}$, and hydrocarbons.
\end{abstract}

\section{Keywords}


Gold nanoparticle; NOx sensing, XPS, spectroscopic size effects, SAE

\section{Introduction}

The use of gold nanoparticles (Au-NPs) can be traced back to the $5^{\text {th }}$ or $4^{\text {th }}$ century B.C. in Egypt and China. During the Roman Age, metal nanoparticles were used for the production of colored glass and pottery, such as the well known Lycurgus Cup, dating back to the $4^{\text {th }}$ Century B.C. [1]. The first "pure" sample of colloidal gold was prepared in 1857 by Michael Faraday, who reduced a gold chloride solution by means of phosphorous. Faraday was the first to attribute the particular red color of that colloidal suspension to the infinitely minute sized gold particles, that he called "activated gold" [2].

In the last decades, gold nanoparticles (Au-NPs) have attracted a great research interest due to their possible application in different fields, such as catalysis [3], optics [4], medicine [5], microelectronics [6], sensor technology [7]. Noteworthy, Au-NPs show interesting size- and shapedependent physicochemical properties [8-12]. In the bulk form, gold is considered an inert material; on the contrary, when finely dispersed at the nanometer scale, its chemical reactivity dramatically increases, as a function of the nanophase size, shape, composition, morphology dispersion, and crystalline status [13-15]. Au-NPs have not completely fulfilled the initial expectations, though, when used as catalyst active material, because of their substantially low catalytic activity, attributed to the completely filled d-band. Nevertheless, it has been found that a relatively high number of chemical reactions can be catalyzed by gold structures in the nanometer range [13]. Just to provide a few examples, in a recent report, the activity of Au-NPs was investigated in the catalytic reduction of aromatic nitro-compounds [16] and a review by Haruta et al. [14] showed the efficiency of supported Au-NPs in promoting $\mathrm{CO}$ oxidation and propylene epoxydation. NP-based gas sensors have been frequently investigated in these years since they offer several advantages, namely: increased surface area-volume ratio and new reactivity properties, thus resulting into improved sensing performance levels, potentially involving all the sensor figures of merit: sensitivity and 
selectivity of the detection, as well as response and recovery time [17]. Frequently, the NP sizedependent properties have been exploited to tune the sensor features [18]. The environmental importance of nitrogen oxides $\left(\mathrm{NO}_{\mathrm{x}}\right)$, that are correlated to a number of health diseases and pollution issues [26], is continuously stimulating an intense academic and industrial research for the development of NP-based $\mathrm{NO}_{\mathrm{x}}$ sensors.

The first example of Au-NP based gas-sensor was proposed in 1998 [19], subsequently, other sensing applications of Au-NPs have followed, mainly based on the use of thiol-capped Au-NPs [20-21], and/or with several different functionalities [22]. Self-assembled coatings from Au-NPs and dendrimers [23], gold nano-triangles [24], were investigated, as well. Moreover, in reference 25 , the sensitivity of nanostructured gold systems was clearly shown to be affected by the particle size. In 1999, Lu et al. [27] extensively studied the chemistry of the $\mathrm{NO}_{\mathrm{x}}$-gold surface system, which constitutes the supporting idea of developing $\mathrm{Au}$ sensing layers for $\mathrm{NO}_{\mathrm{x}}$ detection. In 2001 , a new Field Effect gas sensor based on a thermally evaporated nanostructured Au film was proposed for the detection of $\mathrm{NO}_{2}$ [28]. The sensor showed lower or negligible sensitivity towards interfering species like $\mathrm{H}_{2}$ and $\mathrm{CO}$, and a preferential detection of $\mathrm{NO}_{2}$, with respect to $\mathrm{NO}$; interestingly, better results were obtained in the presence of thinner gate layers with smaller Au-grain sizes. In another study of the same year, Au-doped micro-porous silicon layers were used for the detection of $\mathrm{NO}_{\mathrm{x}}$, with a comparable device response to both $\mathrm{NO}$ and $\mathrm{NO}_{2}$ [29]. Steffes an coworkers. outlined the improvement in the sensing properties of Indium oxides towards $\mathrm{NO}_{2}$ in presence of $\mathrm{Au}-\mathrm{NPs}$ [30]. Langmuir-Schaeffer layers of thiol-stabilized Au-NPs were proven to be sensitive towards $\mathrm{NO}_{2}$ at the low ppm concentration level, too [31]. Recently, Parthangal et al. assembled a sensor device using a $\mathrm{Au}$ nanostructured film on the top of zinc oxide nanowires. This sensor showed sensitivity to both reducing (methanol) and oxidizing (nitrogen dioxide) gases at high temperature [32]. Noteworthy, both in early [28] and recent [31] studies on the $\mathrm{NO}_{x} / \mathrm{Au}$ system, slow response 
and/or recovery have been registered; this was explained through peculiar $\mathrm{NO}_{\mathrm{x}} / \mathrm{Au}-\mathrm{NP}$ surface interaction, leading to residual polarization phenomena in the active layers [28].

A great number of methods have been proposed for the preparation of controlled size and shape AuNPs [33-38], and electrochemical techniques are usually less diffused than wet-chemical methods [39-42]. Wet-chemical preparation processes generally provide NPs of almost any possible shape and in a wide size range, while electrochemical routes to gold nanocolloids show some limitations in the nanomateriale size range and they allow the direct preparation of only few morphologies. Moreover, the preparation media need to contain electrolyte species whose presence might be undesired for some applications and their removal from the Au colloidal suspension could be critical or, at least, it could be a source of irreproducibility. On the contrary, in our opinion, one of the main advantages of electrochemical syntheses resides in the absence of chemical reductants and this results in the preparation of cleaner colloidal solutions with no contamination by the reductant excess or by its sub-products.

In this work, the so-called Sacrificial Anode Electrolysis (SAE) has been used for the preparation of morphologically controlled core-shell Au-NPs.

SAE approach was firstly proposed by the research group of M.T. Reetz [43-44] as a versatile and reliable method to prepare core-shell metal nanoparticles composed by a metal core surrounded by an organic shell. In SAE processes, the control of NP morphology is realized by the use of a proper choice of electrochemical parameters and by the cathodic stabilization of the nanophases growing on the electrode surface [45]. In case of Pd-NPs, the electrolysis was proven to afford for a tight control over the core size and the experimental results were in good agreement with the fundamentals of electrocrystallization theory [42, 46]. Recently, Huang et al. [47] studied SAE processes carried out in the presence of a mixture of surfactants and demonstrated that the size of electrosynthesized Au-NPs can be controlled by the nature and relative amount of the surfactants, 
by the electrochemical parameters employed during the SAE preparation, and by the synthesis temperature.

The present work is aimed at investigating the synthesis of gold nanoparticles using a threeelectrode electrochemical cell in a surfactant solution, with special emphasis on the characteristics of the gold nanoparticles produced. In particular, the effect of current density, surfactant carbon chain length and annealing time has been investigated. The morphology and composition of nanomaterials electrosynthesised by SAE processes were carefully assessed using UV-Vis Absorption Spectroscopy (UV-Vis), X-Ray Photoelectron Spectroscopy (XPS), Scanning Electron Microscopy (SEM) and Transmission Electron Microscopy (TEM). Finally, electrosynthesized AuNPs were investigated as active gate material in field effect capacitive sensors, showing interesting selectivity features in the detection of nitrogen oxides.

\section{Experimental}

\subsection{Au-NPs electrochemical synthesis}

Au-NPs have been electrosynthesized by means of the so-called Sacrificial Anode Electrolysis, [43-44] using a three-electrodes cell equipped with an $\mathrm{Ag} / \mathrm{AgNO}_{3}(0.1 \mathrm{M}$ in acetonitrile) reference electrode, a gold anode and a platinum cathode. Electrode area was of about $3 \mathrm{~cm}^{2}$. The electrolytic solution was composed of a $0.1 \mathrm{M}$ tetra-alkyl-ammonium salt $\left(\mathrm{NR}_{4} \mathrm{Cl}\right.$, with $\left.\mathrm{R}=\mathrm{C}_{4}, \mathrm{C}_{8}, \mathrm{C}_{12}\right)$ dissolved in tetrahydrofuran/acetonitrile (THF/ACN, ratio 3:1). The ammonium salts were used as both particle stabilizer and supporting electrolyte. During the process, the cell was kept under a nitrogen atmosphere and the electrolysis charge was usually set at about $300 \mathrm{C}$. The nanocolloid concentration was calculated by weighting the Au anode before and after the process, to determine the amount of electro-dispersed metal. SAE electrochemical route offered several advantages in terms of reduction of the overall preparation cost, high morphological and chemical stability, as 
well as the possibility of easily tuning the nanoparticle size, being the NP diameter correlated to the process parameters, and particularly to the applied current density $\left(\mathrm{j}_{\mathrm{app}}\right)$.

\subsection{Morphological and Surface chemical characterization}

SEM characterization of annealed Au-NPs was carried out using a LEO 1550 VP Field Emission Scanning Electron Microscope. Transmission Electron Microscopy (TEM) images were obtained by means of JEOL-2010 and Philips 400 T TEM facilities.

Surface elemental characterization was performed by means of $\mathrm{X}$ ray Photoelectron Thermo VG Theta Probe spectrometer equipped with a micro-spot monochromatized Al K $\alpha$ source. Both survey and high-resolution spectra were acquired in fixed analyzer transmission mode with a pass energy of $150 \mathrm{eV}$ and $100 \mathrm{eV}$, respectively. As-synthesized colloids were cast as thin film onto a platinum plate, in order to minimize the onset of differential charging surface phenomena that may appreciably modify the photoelectron peak FWHM, shape, and baseline.

\subsection{Gas sensing device configuration and measurement setup}

The sensing devices employed in this study were field effect MIS (Metal-InsulatorSemiconductor) capacitors with a gate electrode covered by a layer of catalytically active Au-NPs. The capacitive sensor consisted of p-doped $\mathrm{Si}$ as semiconductor, with a thermally grown oxide as insulator. Above this, $\mathrm{Cr} / \mathrm{Au}$ bonding pads were evaporated. The ohmic backside contact consisted of evaporated annealed A1. The sensor device (a ceramic heater) and a Pt-100 element were mounted on a 16-pin holder. A fixed volume $(0.5 \mu \mathrm{l})$ of Au-NPs solution was drop-cast onto the $\mathrm{SiO}_{2}$ surface, partially overlapping the bonding pads. The as-deposited NPs film showed poor electrical conductivity. To increase the film conductivity and enhance its stability, Au-NPs were annealed at $200{ }^{\circ} \mathrm{C}$ for 1 hour. 4-probe measurements showed that the resistivity of annealed NPs film was in the range of $5 \times 10^{-7}$ to $1 \times 10^{-6} \mathrm{ohm} \cdot \mathrm{m}$. 
During exposure to the gas, the sensor holders were mounted in aluminum blocks connected to the gas line. A computer-controlled gas mixing system was used to select the concentration of gases flowing over the sensor surface. The mixing system was connected to a Multi Capacitance Meter (MCM), making possible to measure voltage at constant capacitance for several devices simultaneously. The device output signal was the voltage measured at constant capacitance during the exposure to the test gas. Sensing measurements were performed at $150^{\circ} \mathrm{C}$ with $\mathrm{N}_{2} / \mathrm{O}_{2}$ $(90 \% / 10 \%)$ as carrier gas. Device response towards $\mathrm{NO}$ and $\mathrm{NO}_{2}$ was found to be almost identical. Consequently, the device sensitivity towards nitrogen oxides (generically indicated as $\mathrm{NO}_{\mathrm{x}}$ species) was investigated by using only one of them: $\mathrm{NO}_{2}$. Analyte pulses were set in the concentration range comprised between 50 and $400 \mathrm{ppm}$. Any test gas pulse was followed by a pulse of background gas of the same duration.

\section{Results and Discussion}

\subsection{Au-NPs electrosynthesis and UV-Vis characterization}

In the present study, we aimed at systematically addressing the pros and cons of SAE routes to Au-NPs stabilized by a single capping agent at room temperature. In a first set of experiments, AuNPs have been electrosynthesized in galvanostatic mode, in presence of tetra-octyl-ammonium chloride (TOAC) as stabilizer, by varying $\mathrm{j}_{\text {app }}$ from $-0.50 \mathrm{~mA} \cdot \mathrm{cm}^{-2}$ to $-15.00 \mathrm{~mA} \cdot \mathrm{cm}^{-2}$ (individual SAE data not reported). For every $j_{\text {app }}$, three samples have been prepared and the process efficiency $\eta \%$ was calculated, $\eta \%$ being comprised between 20 and $70 \%$, as a function of the experimental conditions and of a certain sample-to-sample variation. An increase in the mean measured voltage $<\mathrm{E}(\mathrm{V})>$ was observed when increasing $\mathrm{j}_{\mathrm{app}}$, and this parameter also showed a certain sample-tosample dependence, too. Due to these sample-to-sample variations, $\eta \%$ values were then averaged for further data processing. According to $\mathrm{j}_{\mathrm{app}}$, and to the mean value of $\eta \%$, the effective current density $\left(\mathrm{j}_{\text {eff }}\right.$, defined as $\mathrm{j}_{\mathrm{eff}}=\mathrm{j}_{\mathrm{app}} \cdot\left\langle\eta \%\right.$ ) was estimated to vary from $-0.09 \mathrm{~mA} \cdot \mathrm{cm}^{-2}$ to $-4.12 \mathrm{~mA} \cdot \mathrm{cm}^{-2}$. 
Soon after their preparation, pristine colloids were subjected to an UV-Vis spectroscopic characterization, providing the peak position $\left(\lambda_{\max }\right)$ and the full width at half maximum (FWHM) values of the Au-NPs plasmon resonance bands-are reported in Table 1 . The relatively low mean process efficiency and sample-to-sample variations were attributed to the occurrence of side electrochemical processes involving solvent impurities (e.g. traces of water and, most of all, contaminants deriving from the stabilizer commercial batch), and/or stabilizer electro-degradation. The production of amines and/or molecular chlorine (see XPS data in the following, for details), possibly physi- or chemi-sorbed on the surface of the cathode, might have significantly interfered with the SAE efficiency and reproducibility, too.

\subsection{Au-NPs UV-Vis characterization}

Link et al. [48] demonstrated a correlation between the FWHM of plasmon resonance peaks and the particle diameter $\left(\mathrm{d}_{\mathrm{Au}}\right)$ of aqueous Au-nanocolloids. Particularly, the FWHM decreased while increasing the diameter with a minimum value falling at around $\mathrm{d}_{\mathrm{Au}}=25 \mathrm{~nm}$. After this value, for larger particles, the FWHM increases again. Wilcoxon et al. [49] reported, for Au-NPs, that the position and the FWHM of the plasmon resonance peaks depend on both core diameter and particle shape. The authors reported a red-shift of the plasmon resonance peak as the particle diameter is increased. In the present work, we observed a correlation between the variation of the effective current density $\mathrm{j}_{\mathrm{eff}}$ and the nanocolloid spectrophotometric features, namely the peak position and FWHM. Figure 1 and the panel "a" of Figure 2 show that the plasmon resonance peak position and FWHM clearly depend on $\mathrm{j}_{\text {eff }}$, thus indicating a NP size change upon varying $\mathrm{j}_{\text {eff }}[49]$ ]. The peak position $\lambda_{\max }$ shifted from about $522 \mathrm{~nm}$ to higher wavelengths (e.g. $528 \mathrm{~nm}$ ) while changing $\mathrm{j}_{\text {eff }}$ to less cathodic values. The peak FWHM proved to be a more suitable parameter for studying the correlation between $\mathrm{j}_{\text {eff }}$ and NP size and spectroscopic effects. In fact, the peak width showed a marked and linear decrease as $\mathrm{j}_{\text {eff }}$ was increased, thus indirectly showing that the Au-NPs core diameter changes with $\mathrm{j}_{\mathrm{eff}}$ and -given the observed trends- it should have been smaller than $25 \mathrm{~nm}$ 
[48]. As an example, in Figure 2b, the UV-Vis absorption peaks of Au-NPs prepared at $j_{\text {app }}=-5.00$ $\mathrm{mAcm}^{-2}$ and $\mathrm{j}_{\mathrm{app}}=-10.00 \mathrm{mAcm}^{-2}$ are reported. A wider FWHM can be clearly detected for the colloid prepared at $\mathrm{j}_{\text {app }}=-10.00 \mathrm{mAcm}^{-2}$, with respect to $\mathrm{j}_{\text {app }}=-5.00 \mathrm{mAcm}^{-2}$; on the contrary, $\lambda_{\max }$ is only slightly shifted.

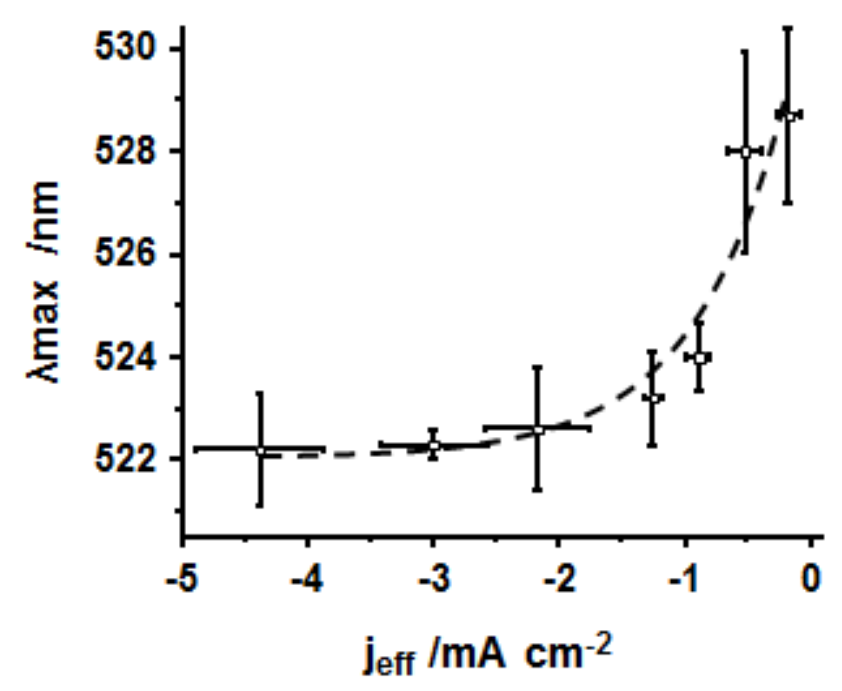

Figure 1. Plasmon resonance peak mean position $\left(\lambda_{\max }\right)$ changes as a function of $j_{\text {eff. }}$ The error bars represent the standard deviation for the mean wavelength and $j_{\text {eff }}$ values $(n=3$ samples $)$.

\subsection{Au-NPs TEM characterization}

The existence of a core size modulation while changing $\mathrm{j}_{\text {eff }}$ from $-0.09 \mathrm{mAcm}^{-2}$ to $-4.12 \mathrm{mAcm}^{-2}$, was confirmed by direct TEM characterizations. Typical micrographs are reported in Figure 3 and are relevant to Au-NPs electrosynthesized at: (a) $\mathrm{j}_{\text {eff }}=-0.14 \mathrm{~mA} \cdot \mathrm{cm}^{-2}$, (b) $\mathrm{j}_{\text {eff }}=-3.83 \mathrm{~mA} \cdot \mathrm{cm}^{-2}$, (c) $\mathrm{j}_{\mathrm{eff}}=-4.12 \mathrm{~mA} \cdot \mathrm{cm}^{-2}$. The dimensional histograms (see insets in the same Figure) showed that mean core diameters were all below the threshold of $25 \mathrm{~nm}$ and particularly they were comprised in the range between $5.4 \mathrm{~nm}$ and $7.9 \mathrm{~nm}$. Even though $\mathrm{j}_{\mathrm{eff}}$ shifted from $-0.14 \mathrm{~mA} / \mathrm{cm}^{-2}$ to $-4.12 \mathrm{~mA} / \mathrm{cm}^{-2}$, a core diameter change of merely $2.5 \mathrm{~nm}$ has been observed. Nevertheless, for the same $\mathrm{j}_{\text {eff }}$ variation, greater differences can be observed for the Au-NPs dimensional dispersion. In the case of $\mathrm{j}_{\mathrm{eff}}=$ $0.14 \mathrm{~mA} \cdot \mathrm{cm}^{-2}$, the particles possessed a quasi-spherical and regular shape, resembling the shape of a micellar environment that is compatible with the presence of the cationic quaternary ammonium 

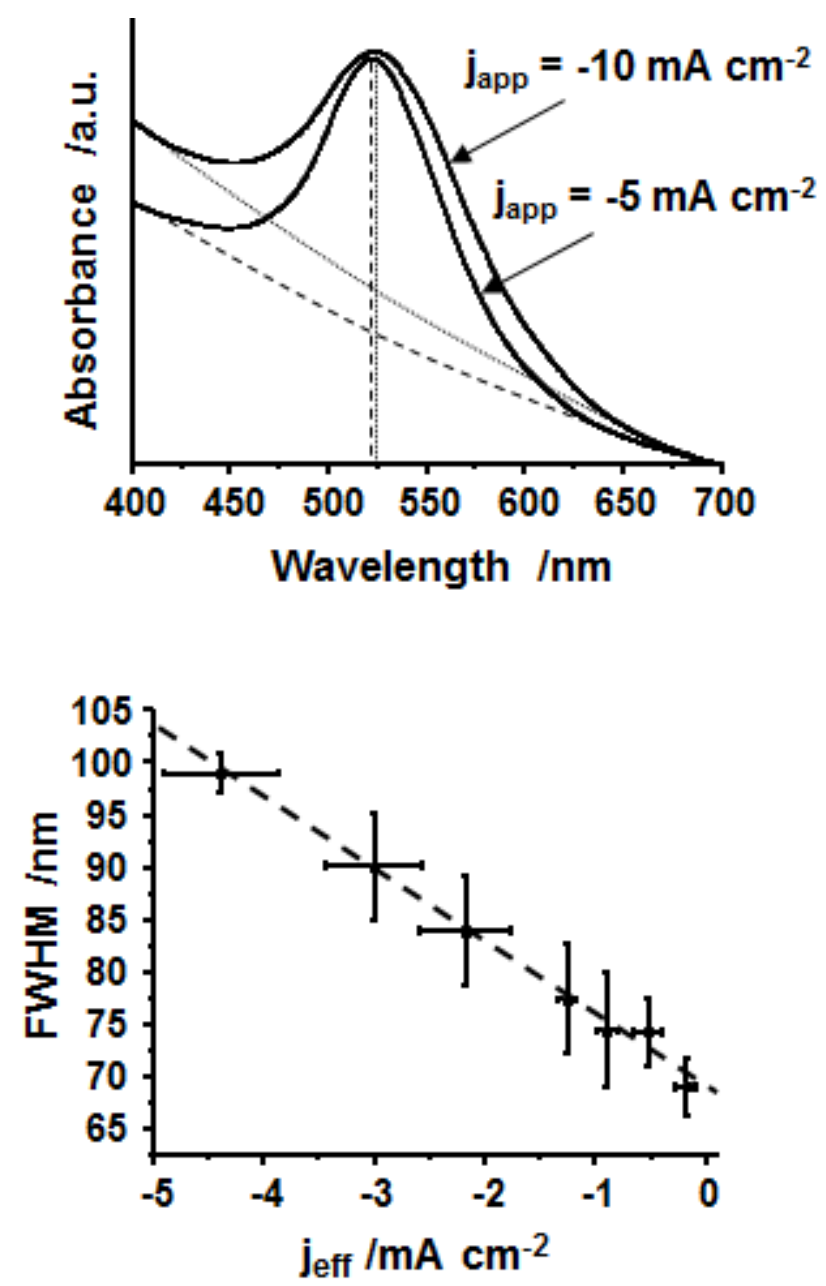

Figure 2. Panel a. Plasmon resonance peak full width at half maximum (FWHM) changes as a function of $j_{\text {eff. }}$. The error bars represent the standard deviation for the mean peak width and $j_{\text {eff }}$ values ( $\mathrm{n}=3$ samples). Panel b. Plasmon resonance spectra for Au-NPs/TOAC electrosynthesized at $\mathrm{j}_{\text {app }}=-5.00 \mathrm{mAcm}^{-2}$ (inner curve) and $\mathrm{j}_{\text {app }}=-10.00 \mathrm{mAcm}^{-2}$ (outer curve) show clear difference in their FWHM values, while the peak $\lambda_{\max }$ values are only slightly different. Baselines, used to calculate peak parameters, are reported for each spectrum.

surfactant. Moreover, the size dispersion was as small as $13 \%$ of the mean particle diameter $\left(d_{\text {TEM }}=7.9 \pm 1.0 \mathrm{~nm}\right.$, see panel "a" of Figure 3). In the case of $j_{\text {eff }}=-3.83 \mathrm{~mA} \cdot \mathrm{cm}^{-2}$, the diameter decreased and the dimensional dispersion increased up to $25 \%$ of the core dimension $\left(\mathrm{d}_{\mathrm{TEM}}=6.2 \pm 1.6\right.$ $\mathrm{nm}$, panel "b" of Figure 3$)$. The use of a more negative current density $\left(\mathrm{j}_{\mathrm{eff}}=-4.12 \mathrm{mAcm}^{-2}\right.$ ) gave rise to a further slight decrease in size, although the dimensional dispersion was broadened to $\sim 40 \%$ of the mean diameter $\left(d_{\text {TEM}}=5.4 \pm 2.2 \mathrm{~nm}\right.$, see panel "c" of Figure 3$)$. Moreover, the TEM image in panel "c" of Figure 3, shows the presence of non spherical nanoclusters, too. The TEM characterization revealed definitely that, by changing $j_{\text {eff }}$ just a limited modulation of particle 


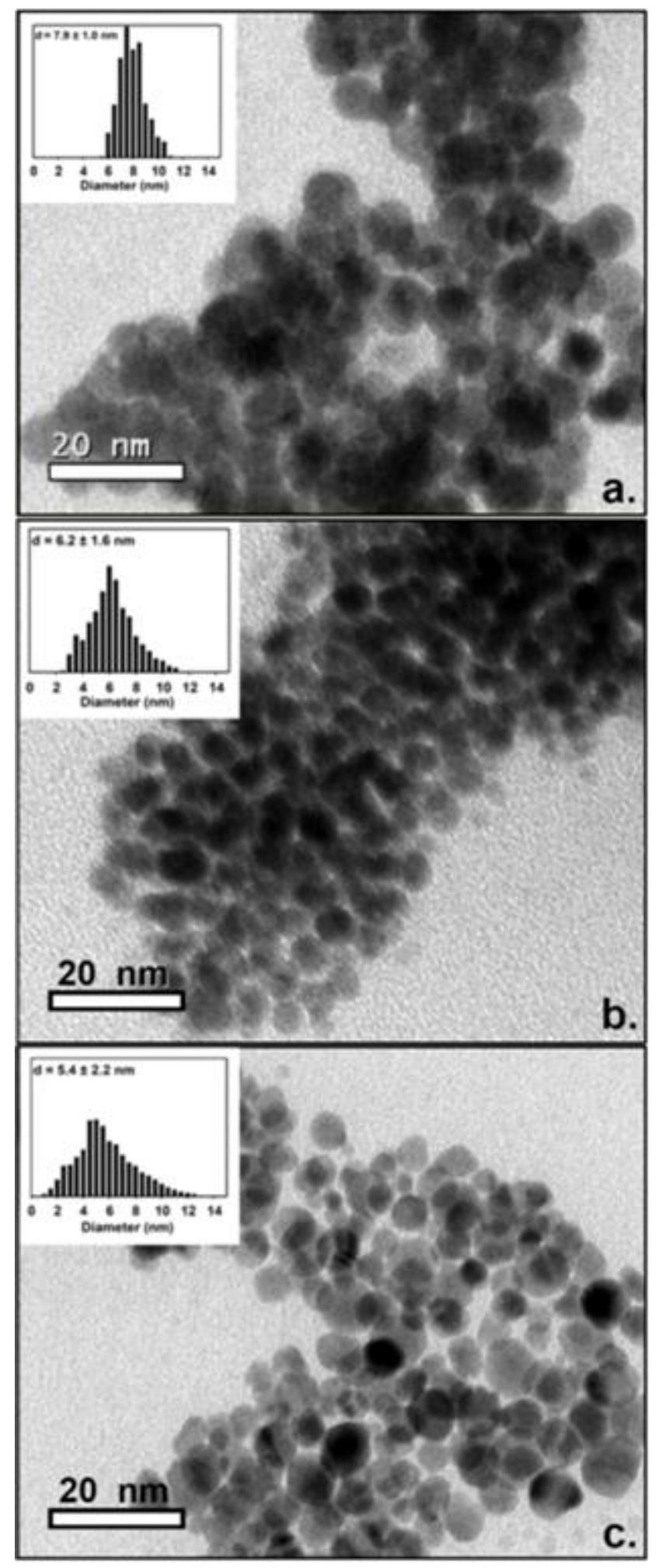

Figure 3. TEM images and dimensional dispersion histograms (insets) for Au-NPs/TOAC electrosynthesized at (a) $\mathrm{j}_{\mathrm{eff}}=-0.14 \mathrm{mAcm}^{-2}, \mathrm{~N}_{\mathrm{NPs}}=617$ particles; (b) $\mathrm{j}_{\mathrm{eff}}=-3.83 \mathrm{mAcm}^{-2}, \mathrm{~N}_{\mathrm{NPs}}=$ 676 particles; (c) $\mathrm{j}_{\mathrm{eff}}=-4.12 \mathrm{mAcm}^{-2}, \mathrm{~N}_{\mathrm{NPs}}=621$ particles. 
diameter could be obtained. In addition, the irregular morphology observed in some samples obtained at higher current density could be attributed to cross-reactivity involving Au-NPs with different size or electrolyte impurities, through Ostwald ripening and/or aggregation processes, with a consequent partial loss of spherical morphology.

\subsection{Au-NPs XPS surface characterization}

The surface chemical characterization of Au-NPs stabilized by TOAC and prepared at different $j_{\text {eff }}$ values has been performed by means of x-ray photoelectron spectroscopy (XPS) to assess the surface elemental composition and chemical states.

The results for the surface elemental analysis of AuNPs prepared at different current densities are reported in Table 1. Noteworthy, samples prepared at different $j_{\text {eff }}$ values possess a comparable surface elemental composition. In all cases, carbon, nitrogen and chlorine are the most abundant elements detected on the nanostructured film surface. Signals from the quaternary ammonium moieties dominate the surface spectra and this is due to the high concentration of the surfactant, that is used both as stabilizer and as base-electrolyte during the preparation. Gold and oxygen were detected, too, although at a lower concentration levels. It should be noticed that Au surface atomic percentage showed a certain sample-to-sample dependence. This could be attributed to the solution casting procedure and to the limited film-forming properties of the surfactant, that is present in large excess in the colloidal NP suspension. Typical XPS chemical speciation results are reported in Table 2. In case of signals composed by a single chemical environment, e.g. C12p and O1s regions, the photoelectron peaks falling at $\mathrm{BE}$ values respectively equal to $196.4 \pm 0.2 \mathrm{eV}$ and $532.4 \pm 0.2 \mathrm{eV}$ were attributed to chloride species (as counterion of the tetra-alkyl-ammonium cation) and to water adsorbed on the surface of the particle film. The $\mathrm{C} 1 \mathrm{~s}$ region showed two chemical states, the main component, falling at $\mathrm{BE}=284.8 \pm 0.1 \mathrm{eV}$, was attributed to aliphatic carbon, whereas the component at $\mathrm{BE}=286.2 \pm 0.1 \mathrm{eV}$ was attributed to $\underline{\mathrm{C}}-\mathrm{N}^{+}$species, deriving from the ammonium stabilizer. The 
N1s curve-fitting also showed two chemical states. The component at higher values (BE $=401.8 \pm 0.1 \mathrm{eV}$ ) was attributed to quaternary nitrogen, while that falling at lower values $(\mathrm{BE}=398.1 \pm 0.2 \mathrm{eV})$, was attributed to aminic species, formed during the possible electrodegradation of the ammonium salt. In the Au4f high resolution region, two chemical states were detected. The first one, falling at lower BE values, was attributed to Au in the elemental oxidation state. The position of the $\mathrm{Au}_{4 \mathrm{f} 7 / 2}$ peak $\left(\mathrm{BE}_{\mathrm{Au} 4 \mathrm{f7} / 2}=83.0 \pm 0.1 \mathrm{eV}\right)$ was significantly lower than that expected for bulk metallic $\mathrm{Au}\left(\mathrm{BE}_{\mathrm{Au} 4 \mathrm{f} 7 / 2}=84.0 \mathrm{eV}\right)$ [50]. This is reasonably due to initial state sizeeffects, already highlighted for very small gold particles [51]. Noteworthy, differently from other nano-systems that showed a BE increase in the case of particles with respect to homologous bulk material [52-53], in the case of Au-NPs, a decrease in the $\mathrm{BE}_{\mathrm{Au} 4 \mathrm{f} 7 / 2}$ was detected. The doublet falling at higher binding energies $\left(\mathrm{BE}_{\mathrm{Au} 4 \mathrm{f} 7 / 2}=84.8 \pm 0.1 \mathrm{eV}\right)$ was attributed to $\mathrm{Au}$ (I) chlorides, most probably as $\left(\mathrm{NR}_{4}\right) \mathrm{AuCl}_{2}$ species [54]. No doublet belonging to $\mathrm{Au}(\mathrm{III})$ species $\left(\mathrm{BE}_{\mathrm{Au} 4 \mathrm{f} 7 / 2}=87.4 \mathrm{eV}\right)$ was detected [55]. It should be pointed out that the relative abundance of the nano-Au(0)/Au(I) chemical environments was sample-to-sample dependent. In particular, the higher the Au-NPs concentration in the colloidal solution, the lower the amount of $\mathrm{Au}(\mathrm{I})$ chlorides. Presumably, $\mathrm{Au}(\mathrm{I})$ species are involved -in the form of chloro-complexes- in the electrostatic interactions with the positively charged particle surface, as already demonstrated for core-shell Pd- and Cu-NPs [52-53].

\subsection{Effects of the surfactant alkyl-ammonium chain length}

According to what was demonstrated by the group of M.T. Reetz in 1995 in case of SAE-prepared Pd-NPs [45], the modulation of Au-NPs overall diameter (given by the sum of the shell thickness and the core diameter) may be performed by increasing the carbon chain length for the alkylammonium salt. The carbon chains are supposed to assume a roughly stretched conformation within the organic shell, thus making possible a quite uniform distribution of the nitrogen cations. The shell may not be considered as an ordered system though, due to the chains' random orientation, its 
thickness is expected to be roughly proportional to the carbon chain length. The effect of the chain length on the core diameter of Au-NPs was investigated in this study since it should have been expected that the longer chain prevents the Au cluster growth, possibly due to a certain chain ability to capture the metal clusters, thus resulting in the synthesis of small particles. Au-NPs were electrosynthesized at $\mathrm{j}_{\mathrm{app}}=-10.00 \mathrm{mAcm}^{-2}$, using tetra-butyl-ammonium chloride (TBAC), TOAC and tetra-dodecyl-ammonium chloride (TDoAC). The UV-Vis characterization revealed that the peak position shifted from $519.3 \pm 1.5$ to $525.5 \pm 1.5 \mathrm{~nm}$, and the peak width decreased while decreasing the chain length from dodecyl $\left(\mathrm{C}_{12}\right)$ to butyl $\left(\mathrm{C}_{4}\right)$, both evidences revealing a NP core size increase [49]. Reasonably, Au-NPs core diameter had to be smaller than $25 \mathrm{~nm}$ [48]. No matter the surfactant chain length, XPS characterization results indicated a surface composition in which carbon, nitrogen and chlorine were the most abundant elements (see Table 4). The interpretation of the results of Table 4 is similar to what already discussed in the case of data from Table 1 of paragraph 3.3. Moreover, the surface chemical speciation analysis for TBAC- and TDoACstabilized Au-NPs gave results very similar to those of Table 2, too; this occurred both in terms of chemical states peak position and relative abundance. In particular, the BE values of the $\mathrm{Au}_{4 \mathrm{f} 7 / 2}$ photoelectron peaks, for the Au elemental and $\mathrm{Au}(\mathrm{I})$ oxidation states, were precisely alike across the different shell particles: $\mathrm{BE}_{\mathrm{Au} 4 \mathrm{f} 7 / 2}=83.0 \pm 0.1 \mathrm{eV}$ and $\mathrm{BE}_{\mathrm{Au} 4 \mathrm{f7} / 2}=84.8 \pm 0.1 \mathrm{eV}$, respectively, [54] with relative abundances for nano- $\mathrm{Au}(0)$ and $\mathrm{Au}(\mathrm{I})$ chemical environments that depended on $\mathrm{Au}-\mathrm{NPs}$ concentration. The developing dimensional effect, attributed to the stabilizer carbon chain, could be hardly revealed from the nano- $\mathrm{Au}(0) \mathrm{Au}_{4 \mathrm{f} 7 / 2}$ peak parameters (peak position and FWHM). The influence of the surfactant chain length on the NP core diameter could not be excluded based on these spectroscopic results, but possibly, there was no such size change that would induce any appreciable differences in the Au photoelectron peak features.

\subsection{TEM characterization}


Au-NPs stabilized by quaternary ammonium species with different chain length were then characterized by means of direct TEM measurements and typical micrographs are reported in Figure 4. The dimensional distributions, taken from the inset histograms, confirmed that NP core diameter was not significantly influenced by the chain length, as the mean NP core diameters were comprised in the range $4.9 \mathrm{~nm} \leq \mathrm{d}_{\text {TEM }} \leq 7.2 \mathrm{~nm}$. Greater differences were found on the particle size dispersion, that was broader in the case of TBAC-capped particles $(\sigma \sim 40 \%)$, while $\mathrm{The}_{8^{-}}$and $\mathrm{C}_{12^{-}}$ capped NPs showed a more regular and spherical morphology with a smaller size dispersion $(\sigma \sim$ 20\%). TBAC turned out a sparely stabilizing salt, with respect to TOAC and TDoAC, probably because of the short $\mathrm{C}_{4}$ chains were not able to give rise to closed and compact shells around the particle growing nucleus, thus leading to a less regular morphology.

\subsection{Au-NPs as gate material for gas sensing}

In a previous publication we tested $\mathrm{Pd}$ - and $\mathrm{Au}$ - nanoparticles produced by the SAE method as gas sensing layers in capacitive Field Effect devices at a temperature of $175^{\circ} \mathrm{C}$ [56]. Here we have investigated the effect of the annealing of these sensing layers which is necessary to get functioning gas sensing devices. Furthermore, we have measured the response of gold nanoparticles as sensing layers at $150{ }^{\circ} \mathrm{C}$. Before gas-sensing applications, Au-NPs/TOAC were drop cast on the device (following the procedure reported in paragraph 2.3) and then subjected to a thermal annealing step at $200^{\circ} \mathrm{C}$ for 1 hour. XPS showed that such a treatment induced the complete conversion of $\mathrm{Au}(\mathrm{I})$ species in nano- $\mathrm{Au}(0)$, that was the only chemical environment detected $(\mathrm{BE}=83.7 \pm 0.1 \mathrm{eV})$. The other XP regions (e.g. N1s, C1s) showed only limited changes in the relative abundances of chemical environments. In particular, N1s region still showed two signals due to amine and ammonium species, although the abundance of the latter chemical environment was significantly increased upon annealing. C1s spectra of annealed samples were composed by two peaks (due to aliphatic and $\underline{\mathrm{C}}-\mathrm{N}$ carbons) and were very similar to that of pristine Au-NPs, that has been discussed 


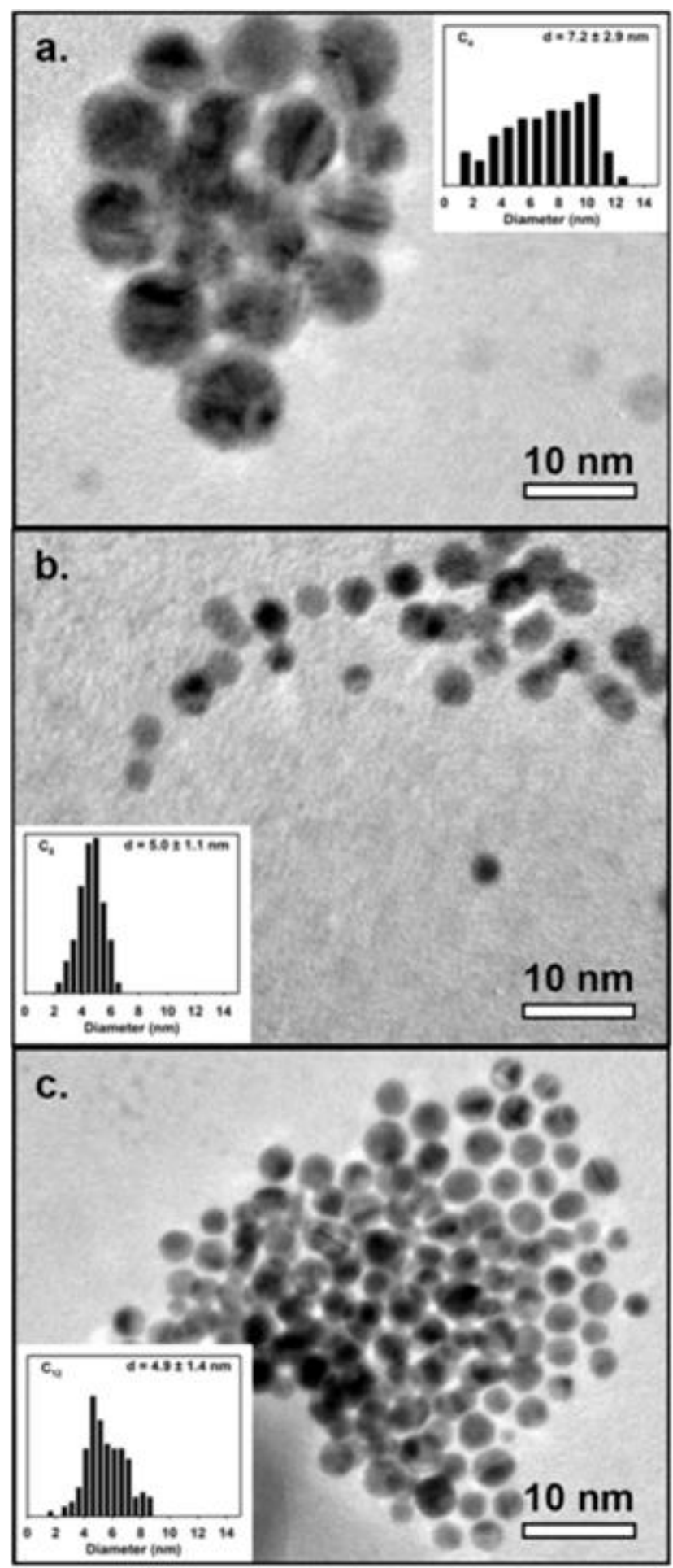

Figure 4. TEM images and dimensional dispersion histograms (insets) of Au-NPs electrosynthesized in presence of (a) TBAC, (b) TOAC and (c) TDoAC at $\mathrm{j}_{\text {app }}=-10.00 \mathrm{mAcm}^{-2}$.

in paragraph 3.3. These evidences can be interpreted similarly to what was reported for other gas sensing materials containing quaternary-ammonium stabilized NPs, like $\mathrm{Pd}-\mathrm{NPs} / \mathrm{SnO}_{\mathrm{x}}$ composites [57]. Thermal annealing is reasonably inducing a partial oxidative degradation of carbon species 
(thus increasing the relative abundance of high-BE carbon peaks) and also Hoffman processes, leading to the degradation of ammonium-functionalities to-amine species (Hoffman processes leading to the increase of the abundance of aminic nitrogens and to the decrease of the oxidized carbon peak). The two opposite effects on the carbon speciation are therefore expected to partially elide each other and this explains why $\mathrm{C} 1 \mathrm{~s}$ spectra show minor changes upon thermal annealing. Moreover the $\mathrm{Au} / \mathrm{C}$ surface atomic ratio was increased from 0.027 (value measured for pristine NPs) to 0.039 and also the layer electrical conductivity was improved. Capacitor sensitivity towards $\mathrm{NO}_{\mathrm{x}}$ was investigated by exposing annealed Au-NPs/TOAC sensors to $\mathrm{NO}_{2}$ target analyte, in a nitrogen/oxygen carrier flow. The Au-NPs sensor was able to detect $\mathrm{NO}_{2}$ at a concentration comprised between 50 and 400 ppm (Figure 5). A typical calibration curve was recorded for this analyte at $150^{\circ} \mathrm{C}$ and is reported in panel "a" of the same Figure. The voltage increase after the exposure to $\mathrm{NO}_{2}$ could be explained by considering that nitrogen oxides behaved as charge donors, thus leading to an increase in the charge density at the Au-NPs-film/insulator interface and thereby influenced the charge carriers in the semiconductors. It should be noted, however, that after the $\mathrm{NO}_{2}$ pulse, the sensor did not recover back to the initial baseline, thus indicating that some irreversible interaction between $\mathrm{NO}_{2}$ and the Au-NPs film took place $[28,31]$. Thus, these data confirmed that slow sensor features were related to the $\mathrm{Au}-\mathrm{NO}_{\mathrm{x}}$ system, no matter of the capping agent and particle size. An experiment aiming at quantifying the sensor selectivity is reported in the left plot of the same figure. The sensor selectivity was studied by using $\mathrm{CO}, \mathrm{H}_{2}, \mathrm{NH}_{3}(250$ and $500 \mathrm{ppm})$ and $\mathrm{C}_{3} \mathrm{H}_{6}$ (50 and $100 \mathrm{ppm}$ ) pulses, since these species are frequently present in the exhaust gases emitted by internal combustion engines and therefore play a key role in affecting the performance level of $\mathrm{NO}_{\mathrm{x}}$ sensors to be employed in automotive applications. A couple of injections were used to monitor the device sensitivity towards each interfering gas at two concentration levels: 50 and $100 \mathrm{ppm}_{3} \mathrm{H}_{6}$, 250 and $500 \mathrm{ppm}$ for $\mathrm{CO}, \mathrm{H}_{2}, \mathrm{NH}_{3}$ respectively. Noteworthy, at the working temperature of $150^{\circ} \mathrm{C}$, 
the Au-NP sensor provided really small responses to $\mathrm{NH}_{3}$ and was not responding at all to $\mathrm{H}_{2}, \mathrm{CO}$ and $\mathrm{C}_{3} \mathrm{H}_{6}$.

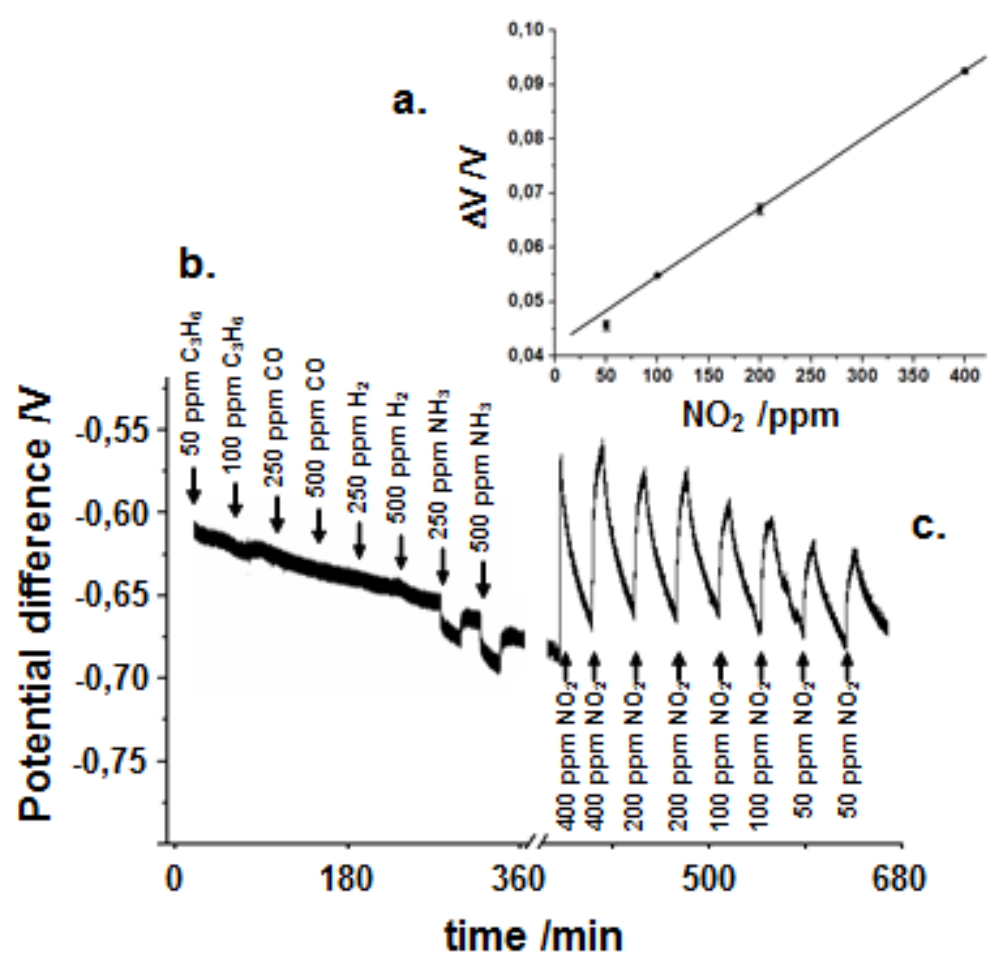

Figure 5. (a) Calibration curve of an Au-NP sensor exposed to $\mathrm{NO}_{2}$ in a nitrogen/oxygen carrier flow ( $\mathrm{n}=2$ replicates); (b) Sensor response, at operative temperature of $150^{\circ} \mathrm{C}$, for several interfering species at 50 and 100 ppm for $\mathrm{C}_{3} \mathrm{H}_{6}$, at 250 ad $500 \mathrm{ppm}$ for $\mathrm{CO}, \mathrm{H}_{2}, \mathrm{NH}_{3}$, in presence of an active gate layer of annealed Au-NPs/TOAC. (c) Sensor response at operative temperature of $150^{\circ} \mathrm{C}$ for several $\mathrm{NO}_{2}$ concentration levels in presence of an active gate layer of annealed Au-NPs/TOAC.

\section{Conclusions}

In this study, core shell Au-NPs were electrochemically synthesized by the so called Sacrificial Anode technique and then used for the surface-modification of gate electrodes employed in FieldEffect capacitor sensors for $\mathrm{NO}_{\mathrm{x}}$ sensing. Nano-colloidal materials were subjected to a morphological and spectroscopic characterization in order to reveal size effects attributed to current density, and surfactant carbon chain length, to select the optimal preparation conditions for the nano-structured sensing films. In particular, UV-Vis spectroscopy and TEM showed that a limited tuning in the core size of pristine Au-NPs is possible by changing the current density and the surfactant carbon chain length. XPS elemental analysis indicated that the surface of pristine material 
is covered by large amount of quaternary ammonium species, that derive from the NPs colloidal solution.

Interesting spectroscopic size effects were outlined by both spectrophotometric and surface spectroscopy results. Au-NP plasmon resonance peaks were shown to shift and change significantly their width as a function of very small core-size differences. Au4f high resolution XP spectra showed the occurrence of marked side-effects, reasonably due to initial-state phenomena.

A mild thermal annealing was then applied to Au-NPs films before their use in gas-sensing devices. The treatment reduced the surface concentration of carbonaceous species, and increased the surface availability of nano-structured gold species. Thermal annealing also induced the conversion of the $\mathrm{Au}(\mathrm{I})$ oxidation state into $\mathrm{Au}(0)$. Au-NP capacitive sensors were able to detect $\mathrm{NO}_{\mathrm{x}}$ at concentration levels ranging from 50 to $400 \mathrm{ppm}$, with good selectivity to $\mathrm{NH}_{3}$ and no response to $\mathrm{CO}, \mathrm{H}_{2}$ and $\mathrm{C}_{3} \mathrm{H}_{6}$. Work is in progress in order to study the effect of higher operating temperatures and of the simultaneous presence in the nanostructured sensing layer of other nano-sized materials.

\section{Acknowledgements}

We acknowledge partial financial support from Regione Puglia - Project DM01 related with the Apulian Technological District on Mechatronics - MEDIS. Drs Capitani, Cervellieri are greatly acknowledged for their skilled help and for useful discussions.

\section{References}

[1] A. Moores, F. Goettmann, New J. Chem. 30 (2006) 1121.

[2] M. Faraday, Pholos. Trans. 147 (1857) 145.

[3] A. Abad, P. Concepcin, A. Corma, Angew. Chem. Int-Ed. Engl. 44 (2005) 4066.

[4] A. K. Sharma, B. D. Gupta, Photonics Nanostr. 3 (2005) 30.

[5] D. Pissuwan, S. M. Valenzuela, M. B. Cortie, Trends Biotech. 24 (2006) 2.

[6] T. L. Chang, Y. W. Lee, C. C. Chen,; F. H. Ko, Microelectr. Eng. 84 (2007) 1698.

[7] C. A. Mirkin, R. L. Letsinger, R. C. Mucic, J. J. Storhoff, Nature 382 (1996) 607.

[8] G. Schmid, Cluster and Colloids: From Theory to Applications; VCH: New York, 1994.

[9] A. Henglein, J. Phys. Chem. 97 (1993) 5457. 
[10] D. L. Feldein, C. D. Keating, Chem. Soc. Rev. 27 (1998) 1.

[11] J. D. Aiken, R.G. Finke, J. Mol. Catal. A 145 (1999) 1.

[12] M. A. El-Sayed, Acc. Chem. Res. 34 (2001) 257.

[13] A. Afzali, C. D. Dimitrakopoulos, T. L. Breen, J. Am. Chem. Soc. 124 (2002) 8812.

[14] M. Haruta, Catalysis Today 36 (1997) 153.

[15] G. J. Hutchings, Catalysis Today, 100 (2005) 55.

[16] S. Panigrahi, S. Basu, S. Praharaj, S. Pande, S. Jana, A. Pal, Ghosh, S. Kumar J. Phys. Chem.

C 111 (2007) 4596.

[17] M. E. Franke, T. J. Koplin,; U. Simon, Small 2 (2006) 36.

[18] G. Jimènez-Cadena, J. Riu, F. X. Rius, Analyst 132 (2007) 1083.

[19] H. Wohltjen; A. W. Snow, Anal. Chem. 70 (1998) 2856.

[20] S. D. Evans,; S. R. Johnson, Y. L. Cheng, T. Shen, J. Mater. Chem. 10 (2000) 183.

[21] J. G. Grate, D. A. Nelson, R. Skraggs, Anal. Chem. 75 (2003) 1868.

[22] H. L. Zhang, S. D. Evans, J. R. Henderson, R. E. Miles, T. H. Shen, Nanotechnology 13 (2002) 439.

[23] T. Vossmeyer, B. Guse, I. Besnard, R. E. Bauer, K. Muellen, A. Yasuda, Adv. Mater. 14 (2002) 238.

[24] A. Singh, M. Chaudhari, M. Sastry, Nanotechnology 17 (2006) 2399.

[25] L. Han, D. R. Daniel, M. M. Mayer, C. J. Zhang, Anal. Chem. 73 (2001) 4441.

[26] http://www.epa.gov/air/urbanair/nox/hlth.html.

[27] X. Lu, X. Xu, N. Wang, Q. Zhang, J. Phys. Chem. A 103 (1999) 10969.

[28] D. Filippini, T. Wei, R. Aragon, U. Weimar, Sens. Actuators B 78 (2001) 195.

[29] C. Baratto, G. Sberveglieri, E. Comini, G. Faglia, G. Benussi, V. La Ferrara, L. Quercia, G. Di Francia, V. Guidi, D. Vincenti, D. Boscarino, V. Rigato, Sens. Actuators B 68 (2000) 74.

[30] H. Steffes, C. Imawan, F. Solzbacher, E. Obermeier, Sens. Actuators B 78 (2001) 106.

[31] M. D. Hanwell, S. Y. Heriot, T. H. Richardson, N. Cowlam, I. M. Ross, Colloids Surf., A 379 (2006) 284.

[32] P. M. P. Parthangal, R. E. Cavicchi, M. R. Zachariah, Nanotechnology 17 (2006) 3786.

[33] Y. Yu, S. Chang, C. R. C. Wang, J. Phys. Chem. B 101 (1997) 6661.

[34] C. J. Murphy; N. R. Jana, Adv. Mater. 14 (2002) 80.

[35] F. Kim, J. H. Song, P. Yang, J. Am. Chem. Soc. 124 (2002) 14316.

[36] Y. Sun; Y. Xie, Science 298 (2002) 2176.

[37] D.V. Left, L. Brandt, J. R. Heath, Langmuir 12 (1996) 4723.

[38] M. I. Baraton, Synthesis, Functionalization and Surface Treatment of Nanoparticles, American Scientific Publishers: California, USA, 2003, Chap.5, pp.67.

[39] N. Cioffi, L. Torsi, N. Ditaranto, G. Tantillo, L. Ghibelli, L. Sabbatini, T. Bleve-Zacheo, M.

D’Alessio, P.G. Zambonin, E. Traversa, Chemistry of Materials, 17 (2005) 5255.

[40] N. Cioffi, N. Ditaranto, L. Torsi, R.A. Picca, E. De Giglio, L. Sabbatini, L. Novello, G.

Tantillo, T. Bleve-Zacheo, P.G. Zambonin, Anal. Bioanal. Chem., 382 (2005) 1912.

[41] M. Faticanti, N. Cioffi, S. De Rossi, N. Ditaranto, P. Porta, L. Sabbatini, T. Bleve-Zacheo, Applied Catalysis B, Environmental, 60 (2005) 73.

[42] E. Ieva, N. Cioffi, invited review chapter, in Nanomaterials: New Research Developments, E.I. Pertsov Ed., Nova Science Publishers.

[43] M. T. Reetz; W. Helbig, J. Am.Chem. Soc. 1994, 116, 7401. 
[44] N. Cioffi, L. Torsi, L. Sabbatini, P. G. Zambonin, T. B. Zacheo, J. ElectroAnal. Chem. 488 (2000) 42.

[45] M. T. Reetz, W. Helbig, S. A. Quaiser, U. Stimming, N. Breuer, R. Vogel, Science 267 (1995), 367.

[46] B. Gollas, J. M. Elliott, P. N. Bartlett, Electrochimica Acta 45 (2000) 3711.

[47] C. J. Huang, P. H. Chiu, Y. H. Wang, K. L. Chen, J. J. Linn, C. F. Yange, J. Electrochem. Soc. 153 (2006) D193.

[48] S. Link, M. A. El Sayed, J. Phys. Chem. B 103 (1999) 4212.

[49] J. P. Wilcoxon, R. L. Williamson, R. Baughman, J. Chem. Phys. 98 (1993) 12.

[50] J. F. Moulder, W. F. Stickle, P. E. Sobol, K. D. Bomben, Handbook of X-ray Photoelectron Spectroscopy; Perkin-Elmer Corporation, Eden Praire: Minnesota, 1992.

[51] J. Radnik, C. Mohr, P. Claus, Phys. Chem. Chem. Phys. 5 (2003) 172.

[52] N. Cioffi, L. Torsi, I. Losito, L. Sabbatini, P.G. Zambonin, T. Bleve-Zacheo, Electrochimica Acta 46 (2001) 4205.

[53] N. Cioffi, N. Ditaranto, L. Torsi, R.A. Picca, E. De Giglio, L. Sabbatini, L. Novello, G. Tantillo, T. Bleve-Zacheo, P.G. Zambonin, Analytical and Bioanalytical Chemistry 382 (2005) 1912.

[55] S. A. Vorobyova, N. S. Sobal, A. I. Lesnikovich, Colloids Surf. A 176 (2001) 273.

[55] T. Muyama, Y. Yonezawa, Langmuir 20 (2004) 5918.

[56] P.S. K. Buchholt, E. Ieva, L.Torsi, N. Cioffi, L. Colaianni, F.Söderlind, P-O. Käll, A. Lloyd Spetz, Electrochemically synthesized Pd- and Au-nanoparticles as sensing layers in $\mathrm{NO}_{\mathrm{x}}$-sensitive Field Effect Devices, in Series: Lecture Notes in Electrical Engineering, vol. 20, Smart Sensors and Sensing Technology, S.C. Mukhopadhyay, G.S. Gupta (eds), Springer, Berlin Heidelberg, Germany, pp.63-75, 2008. ISBN: 978-3-540-79589-6

[57] N. Cioffi, L. Traversa, N. Ditaranto, A. M. Taurino, M. Epifani, P. Siciliano, T. Bleve-Zacheo, L. Sabbatini, L. Torsi, P.G. Zambonin, Microelectronics Journal, 12 (2006) 1620. 


\section{Table Captions}

Table 1. XPS surface elemental analysis for Au-NPs/TOAC electrosynthesized at different $\mathrm{j}_{\text {eff }}$ values.

Table 2. Chemical speciation analysis for Au-NPs/TOAC electrosynthesized at $\mathrm{j}_{\text {eff }}=-2.65 \mathrm{mAcm}^{-2}$. Homologous data relevant to Au-NPs/TBAC and Au-NPs/TDoAC are very similar to those of the present Table.

Table 3. Typical electrochemical and UV-Vis resonance peak parameters for Au-NPs prepared at $\mathrm{j}_{\mathrm{app}}=-10.00 \mathrm{mAcm}^{-2}$ in presence of TBAC, TOAC and TDoAC. The error associated to the plasmon peak position $\left(\lambda_{\max }\right)$ and width $(\mathrm{FWHM})$ is \pm 1.5 and $\pm 2 \mathrm{~nm}$, respectively.

Table 4. XPS surface elemental analysis for Au-NPs/TBAC, Au-NPs/TOAC and Au-NPs/TDoAC nanocolloids electrosynthesized at $\mathrm{j}_{\mathrm{app}}:-10.00 \mathrm{~mA} \cdot \mathrm{cm}^{-2}$. 
Table 1.

\begin{tabular}{ccccccc}
\hline $\mathrm{j}_{\text {app }} / \mathrm{mA} \mathrm{cm}^{-2}$ & $\mathrm{j}_{\text {eff }} / \mathrm{mA} \mathrm{cm}^{-2}$ & $\mathrm{C}(\%)$ & $\mathrm{Au}(\%)$ & $\mathrm{N}(\%)$ & $\mathrm{Cl}(\%)$ & $\mathrm{O}(\%)$ \\
\hline-0.50 & -0.14 & $90.6 \pm 0.5$ & $1.9 \pm 0.2$ & $3.3 \pm 0.5$ & $3.6 \pm 0.5$ & $0.6 \pm 0.5$ \\
\hline-1.00 & -0.48 & $90.5 \pm 0.5$ & $2.7 \pm 0.2$ & $2.8 \pm 0.5$ & $3.4 \pm 0.5$ & $0.6 \pm 0.5$ \\
\hline-2.00 & -0.93 & $90.6 \pm 0.5$ & $2.9 \pm 0.2$ & $2.9 \pm 0.5$ & $2.8 \pm 0.5$ & $0.8 \pm 0.5$ \\
\hline-3.00 & -1.21 & $89.8 \pm 0.5$ & $2.1 \pm 0.2$ & $2.8 \pm 0.5$ & $2.6 \pm 0.5$ & $2.7 \pm 0.5$ \\
\hline-5.00 & -2.65 & $90.4 \pm 0.5$ & $1.7 \pm 0.2$ & $2.9 \pm 0.5$ & $3.1 \pm 0.5$ & $1.9 \pm 0.5$ \\
\hline-10.00 & -3.83 & $89.9 \pm 0.5$ & $2.5 \pm 0.2$ & $2.6 \pm 0.5$ & $3.1 \pm 0.5$ & $1.8 \pm 0.5$ \\
\hline-15.00 & -4.12 & $91.9 \pm 0.5$ & $1.9 \pm 0.2$ & $2.9 \pm 0.5$ & $2.7 \pm 0.5$ & $0.6 \pm 0.5$ \\
\hline
\end{tabular}

Table 2.

\begin{tabular}{ccccc}
\hline & Region & $\mathrm{BE} / \mathrm{eV}$ & Relative abundance $(\%)$ & Attribution \\
\hline \multirow{2}{*}{ Au-NPs/TOAC } & $\mathrm{Au} 4 \mathrm{f}$ & $83.0 \pm 0.1$ & $82 \pm 5$ & Nano-Au(0) \\
\cline { 2 - 5 } & & $84.8 \pm 0.1$ & $18 \pm 5$ & $\mathrm{Au}(\mathrm{I})$ \\
\cline { 2 - 5 } & $\mathrm{C} 1 \mathrm{~s}$ & $284.8 \pm 0.1$ & $88 \pm 5$ & aliphatic carbon \\
\cline { 2 - 5 } & & $286.1 \pm 0.1$ & $12 \pm 5$ & $\underline{\mathrm{C}}^{+}{ }^{+}$ \\
\cline { 2 - 5 } & $\mathrm{N} 1 \mathrm{~s}$ & $398.1 \pm 0.2$ & $23 \pm 5$ & NR$_{3}, \mathrm{NHR}_{2}, \mathrm{NH}_{2} \mathrm{R}$ \\
\hline & $401.8 \pm 0.2$ & $77 \pm 5$ & NR4 $^{+}$ \\
\hline
\end{tabular}

Table 3.

\begin{tabular}{lcccccc}
\hline & $\mathrm{j}_{\text {app }} / \mathrm{mA} \mathrm{cm}^{-2}$ & $\mathrm{j}_{\text {eff }} / \mathrm{mA} \mathrm{cm}^{-2}$ & $\langle\mathrm{E}>/ \mathrm{V}$ & $\eta \%$ & $\lambda_{\text {MAX }} / \mathrm{nm}$ & $\mathrm{FWHM} / \mathrm{nm}$ \\
\hline Au-NPs/TBAC & -10.00 & -3.34 & +1.7 & 50 & 525.5 & 65 \\
\hline Au-NPs/TOAC & -10.00 & -3.83 & +2.1 & 35 & 522.4 & 89 \\
\hline Au-NPs/TDoAC & -10.00 & -3.29 & +1.8 & 47 & 519.3 & 95 \\
\hline
\end{tabular}

Table 4.

\begin{tabular}{lccccccc}
\hline & $\mathrm{j}_{\text {app }} / \mathrm{mA} \mathrm{cm}^{-2}$ & $\mathrm{j}_{\text {eff }} / \mathrm{mA} \mathrm{cm}^{-2}$ & $\mathrm{C}(\%)$ & $\mathrm{Au}(\%)$ & $\mathrm{N}(\%)$ & $\mathrm{Cl}(\%)$ & $\mathrm{O}(\%)$ \\
\hline Au-NPs/TBAC & -10.00 & -3.34 & $81.3 \pm 0.5$ & $1.6 \pm 0.2$ & $5.5 \pm 0.5$ & $6.4 \pm 0.5$ & $5.2 \pm 0.5$ \\
\hline Au-NPs/TOAC & -10.00 & -3.83 & $89.9 \pm 0.5$ & $2.5 \pm 0.2$ & $2.6 \pm 0.5$ & $3.1 \pm 0.5$ & $1.8 \pm 0.5$ \\
\hline Au-NPs/TDoAC & -10.00 & -3.29 & $93.3 \pm 0.5$ & $1.9 \pm 0.2$ & $2.0 \pm 0.5$ & $1.9 \pm 0.5$ & $0.8 \pm 0.5$ \\
\hline
\end{tabular}

